\title{
Solid phase extraction and LC-MS/MS quantification of ibandronate in human plasma
}

\author{
Moustapha E Moustapha ${ }^{1,2}$, Sherif A Abdel-Gawad ${ }^{3,4 *}$ \\ ${ }^{1}$ Department of Chemistry, College of Science and Humanities, Prince Sattam Bin Abdulaziz University, Al-Kharj, 11942. \\ Kingdom of Saudi Arabia, ${ }^{2}$ University Central Laboratory, College of Science and Humanities, Prince Sattam BinAbdulaziz \\ University, Al-Kharj, 11942, Kingdom of Saudi Arabia, ${ }^{3}$ Pharmaceutical Chemistry Department, College of Pharmacy, Prince \\ Sattam BinAbdulaziz University, Al-Kharj, Kingdom of Saudi Arabia, ${ }^{4}$ Analytical Chemistry Department, Faculty of Pharmacy, \\ Cairo University, Cairo, Egypt
}

*For correspondence: Email: sagawad@yahoo.com

Sent for review: 23 October 2019

Revised accepted: 24 May 2020

\begin{abstract}
Purpose: To develop and validate a simple, highly sensitive and accurate method for the quantification of ibandronate (IBN) in human plasma.

Methods: Electrospray ionization liquid chromatography tandem mass spectrometry (LC-MS/MS) in positive ion mode was applied to obtain optimum signals. The parent ion was acquired under collisionactivated dissociation conditions, and the abundant fragments used to design multiple reaction monitoring experiments for monitoring two ibandronate transitions $(\mathrm{m} / \mathrm{z} 376$ to $\mathrm{m} / \mathrm{z} 114$, and $\mathrm{m} / \mathrm{z} 376$ to $\mathrm{m} / \mathrm{z}$ 250). The IBN was isolated from plasma with weak anion exchange solid phase extraction columns with 'on-cartridge' derivatization using tri-methylsilyl-diazomethane (TMSDZ) reagent to convert IBN to tetra-methyl derivative.

Results: The studied drug was successfully extracted from plasma samples without any interference at a retention time of $3.2 \mathrm{~min}$. The matrix effect averaged $110 \%$, indicating that endogenous materials had little effect on ionization. The relationship between plasma analyte concentration and IBN signal area was satisfactorily linear, with correlation coefficient ( $r 2$ ) ranging from 0.9817 to 0.9942 in the concentration range of $0.5-200 \mathrm{ng} / \mathrm{ml}$. The lower and upper limits of quantification (LLOQ and ULOQ) for IBN were 0.5 and $200 \mathrm{ng} / \mathrm{ml}$, respectively. Relative recovery of IBN from plasma after extraction and derivatization at 3 distinct concentrations was 83.93 to $85.06 \%$, relative to standard solutions. The ranges of intra- and inter-day accuracies of quantification of quality controls were $89.39-106.40 \%$, and 90.50 - $107.96 \%$, respectively. Processed plasma IBN extracts were stable in autosampler at 4 OC (91.12 to $103.49 \%)$. Long-term stability in plasma after 30 days at -24 OC ranged from 89.52 to 113.18 $\%$.

Conclusion: This validated LC-MS/MS method can be successfully applied for determination of IBN in pharmacokinetic studies. It is a sensitive and specific assay for plasma IBN in bioequivalence studies.
\end{abstract}

Keywords: Ibandronate, LC-MS/MS, Validation, Derivatization, Solid-phase extraction

This is an Open Access article that uses a fund-ing model which does not charge readers or their institutions for access and distributed under the terms of the Creative Commons Attribution License (http://creativecommons.org/licenses/by/4.0) and the Budapest Open Access Initiative (http://www.budapestopenaccessinitiative.org/read), which permit unrestricted use, distribution, and reproduction in any medium, provided the original work is properly credited.

Tropical Journal of Pharmaceutical Research is indexed by Science Citation Index (SciSearch), Scopus, International Pharmaceutical Abstract, Chemical Abstracts, Embase, Index Copernicus, EBSCO, African Index Medicus, JournalSeek, Journal Citation Reports/Science Edition, Directory of Open Access Journals (DOAJ), African Journal Online, Bioline International, Open-J-Gate and Pharmacy Abstracts 


\section{INTRODUCTION}

Ibandronate sodium (IBN) (Figure 1) is 3-(nmethyl-N-pentyl) amino-1-hydroxypropane1,1diphosphonic acid, monosodium salt, monohydrate which suppresses the ability of osteoclasts to resorb bone [1]. The drug is prescribed for the prevention and treatment of osteoporosis, since it can be used to elevate the mineral density of the bone [2].

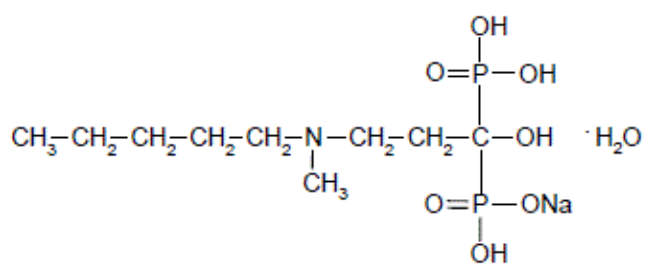

Figure 1: Chemical structure of ibandronate sodium

Analysis of bisphosphonates in pharmaceutical form is very challenging due to a variety of reasons. Most of these compounds lack a chromophore. They are extremely polar, with several functional groups. Moreover, they are not well-retained on HPLC columns. Their ionization efficiency in mass spectrometry, in either negative ion or positive ion modes, is also poor [1]. In a study, HPLC method coupled with analyte derivatization was applied to quantify aminobisphosphonate, and alendronate (ALN) was determined after its extraction with diethylamine (DEA) solid-phase extraction (SPE) cartridge, followed by derivatization with 9fluorenylmethyl [3]. The technique of GS-MS has been used to measure different aminobisphosphonate members, including ALN after their conversion to the more volatile $\mathrm{N}$ isobutoxycarbonyl methyl ester derivatives [4]. Moreover, capillary electrophoresis has been applied to determine bisphosphonates and their impurities [5]. In one study, ELISA technique was applied in quantification of IBN [6], and IBN has also been determined spectrophotometrically via ligand exchange [7].

The technique of LC-MS/MS was recently utilized for determination of aminobisphosphonates in samples after their liquid-liquid extraction and derivatization $[8,9]$. Liquid-liquid extraction has many drawbacks: it is a tedious extraction method, being that it results in emulsion formation. In addition, it can be considered an environment-unfriendly protocol because it consumes large volumes of organic solvents [10]. Solid phase extraction (SPE) is the future prospect for green analytical chemistry due to its simplicity, environment-friendly samplepreparation technique, and low cost in terms of time and solvents [11]. Recently, SPE was applied in the isolation of risedronate and alendronate from serum and urine, followed by derivatization of the four active hydroxyl groups to the corresponding methyl esters using either diazomethane or trimethylsilyl-diazomethane (TMS-DZ) [12].

This study was designed to develop and authenticate an easy, highly sensitive and accurate procedure for the quantification of ibandronate (IBN) in human plasma so as to overcome the drawbacks of liquid - liquid extraction.

\section{EXPERIMENTAL}

\section{Chemicals and reagents}

Ibandronate (IBN) reference material $\left(\mathrm{C}_{9} \mathrm{H}_{24} \mathrm{NNaO}_{8} \mathrm{P}_{2}\right.$, molecular weight $=359.23$ $\mathrm{g} / \mathrm{mol}$ ) was kindly provided by Faculty of Pharmacy, Cairo University, Cairo, Egypt. Formic acid, LC/MS LiChrosolv ${ }^{\circledR}$ Acetonitrile, ammonium formate and tri-methylsilyldiazomethane (2M in hexane) were purchased from TMS-DZ, Sigma-Aldrich; CAS Number 18107-181. The LC/MS-grade water used was supplied by LiChrosolv ${ }^{\circledR}$. Solid phase extraction columns (SPEs) i.e. high-capacity Waters Oasis 6cc SPE columns purchased from Waters Co., USA, were used for combined extraction and derivatization of IBN.

\section{Instrumentation and its optimization}

\section{Mass spectrometry optimization}

Applied Biosystems API3200Q 3-quadrupole mass spectrometer with electrospray probe and interface was used for MS. Electrospray ionization (ESI) was done in the positive ion MRM mode. The MS/MS parameters were: declustering potential (DP): $48 \mathrm{~V}$; collision energy (CE): $28 \mathrm{eV}$ for $\mathrm{m} / \mathrm{z} 376$ to $\mathrm{m} / \mathrm{z} 114$ transition; entrance potential (EP): $4 \mathrm{~V}$; collision cell exit potential $(\mathrm{CXP})$ : $2 \mathrm{~V}$; CEP $=18 \mathrm{~V}$, and ion spray voltage (ISV) was set at 5500 V. Source temperature was $650^{\circ} \mathrm{C}$, curtain gas $=30 \mathrm{psi}$, GS1 $=55$, GS2 $=55$, and collision activated dissociation (CAD) gas was set at 5 psi. Dwell time was maintained at $200 \mathrm{~ms}$. Integration of signal areas was done using data system analyst (version 1.5) running under Windows XP environment.

In order to optimize the electrospray ionization (ESI) for IBN tetra-methyl derivative, the derivative was prepared using IBN working solution $(50 \mu \mathrm{g} / \mathrm{ml})$. After appropriate dilution, the product of the reaction was infused into the mass 
spectrometer ion source in positive ion mode ESI, using a speed of $20 \mu \mathrm{l} / 60 \mathrm{sec}$.

\section{LC-MS/MS}

Chromatographic analysis of tetra-methyl IBN was performed utilizing Waters Sunfire column preceded by an in-line filter. Chromatography was in the isocratic mode of analysis using $\mathrm{CH}_{3} \mathrm{CN}$ and $150 \mathrm{mM} \mathrm{NH}_{4} \mathrm{HCOO}$ at a volume ratio of 28:72 (adjusted to $\mathrm{pH} 3.5$ ) at a speed of 0.75 $\mathrm{mL} / \mathrm{min}$. The column temperature was adjusted to room temperature. The autosampler temperature was maintained at $4{ }^{\circ} \mathrm{C}$. The injection volume was $5 \mu \mathrm{L}$, and the total run and data acquisition took $5 \mathrm{~min}$. The mass spectrometer ion source temperature and the flow rate of desolvation gas were optimized to obtain the best signal-to-noise ratio for IBN derivative. These parameters were checked and deemed consistent for areas or signal-to-noise ratio, or otherwise adjusted before each run. Furthermore, the mass assignment was periodically checked to ensure calibration of the instrument. The change from mass: charge ratio 376 to mass: charge ratio 114 was utilized for quantification. On the other hand, change from mass: charge ratio 376 to mass: charge ratio 250 was used as a confidence transition to confirm the identity of the analyte peak.

\section{Quality control and calibration standard samples}

A stock solution was made by weighing suitable amount of IBN and dissolving it in $5 \mathrm{~mL}$ of deionized water acidified with $\mathrm{HCl}$ to $\mathrm{pH} 4.0$ in a 10$\mathrm{mL}$ volumetric flask. Following vortexing, the volume was brought up to mark with acidified water to yield a final concentration of 5000 $\mu \mathrm{g} / \mathrm{mL}$. Working standard solutions of concentrations 50,5 and $0.5 \mu \mathrm{g} / \mathrm{mL}$ were prepared from the IBN stock solution via serial dilution.

Calibration standards and quality controls were prepared under the same conditions as the samples for analysis. Calibration curves consisted of a blank sample without any additions, and eight samples within the anticipated range of concentrations to be analyzed. To prepare plasma calibration standards, control plasma was spiked with IBN standard solutions. Samples for plasma calibration had concentrations of $0.5,1,2.5,5$, 15, 50, 100 and $200 \mathrm{ng} / \mathrm{mL}$. Low, medium and high concentrations of each quality control sample corresponding to 3,80 and $160 \mathrm{ng} / \mathrm{mL}$, were prepared. All calibration standards were vortex-mixed for $5 \mathrm{~min}$ to ensure proper mixing.
The prepared standards were dispensed in 0.5$\mathrm{mL}$ portions in marked tubes and kept at $-24{ }^{\circ} \mathrm{C}$ together with $\mathrm{QC}$ samples until required for assay. For each assay, one tube of each concentration was thawed for one hour before sample extraction. They were used during the pre-study method validation phase, and also for quality control during the analytical phase.

\section{Extraction procedure of plasma samples}

On the day of assay, samples to be extracted were thawed for one hour. To all tubes, $40 \mu \mathrm{L}$ of $1 \mathrm{M} \mathrm{HCl}$ was added and vortexed. Solid phase extraction (SPE) cartridges were positioned on the extraction manifold. Then, each cartridge was equilibrated with $2 \mathrm{~mL}$ of $20 \mathrm{mM} \mathrm{HCl}$ and washed with $2 \mathrm{~mL}$ of water. Plasma containing IBN was loaded onto the cartridges, followed by washing with $2 \mathrm{~mL}$ of $20 \mathrm{mM} \mathrm{HCl}$, and rinsing with $2 \mathrm{~mL}$ of methanol. An aliquot of $1 \mathrm{~mL}$ of TMS-DZ was added to each cartridge, and the eluate was collected into labeled tubes. Another $1 \mathrm{~mL}$ portion of TMS-DZ was added and combined with previously collected eluates. The collected eluate was evaporated to dryness with nitrogen at $50{ }^{\circ} \mathrm{C}$, reconstituted in $250 \mu \mathrm{L}$ of mobile phase and transferred to autosampler vial. A $5-\mu \mathrm{L}$ portion was injected into the mass spectrometer.

\section{Validation of bioanalytical procedure}

Validation was carried out with respect to parameters such as precision and accuracy, linearity selectivity, sensitivity, recovery, matrix effect, and stability according to US-FDA guidelines.

\section{RESULTS}

\section{Method development}

The mass spectrum of IBN tetra-methyl showed base peak for the protonated molecular ion at $\mathrm{m} / \mathrm{z} 376$ (Figure 2). Following the optimization of single quad signal, the collision-activated dissociation spectra (CAD) for the protonated molecular ion was acquired at different collision energies to optimize the output signal. Tetramethyl IBN yielded two major fragments at $\mathrm{m} / \mathrm{z}$ 114 and $\mathrm{m} / \mathrm{z} 250$. Figure 3 shows the product ion spectrum of tetra-methyl IBN. These two fragments formed the basis for the design of the MRM experiments used for analysis.

Figure 4 and Figure 5 show MRM chromatograms for the two transitions of IBN derivative obtained from plasma calibrators under the experimental conditions mentioned above. The shift from mass: charge ratio 376 to 
mass: charge ratio 114 was applied for quantification, while the shift from mass: charge ratio 376 to mass: charge ratio 250 was used as a confidence transition to identify the LC-MS/MS peak for the analyte.

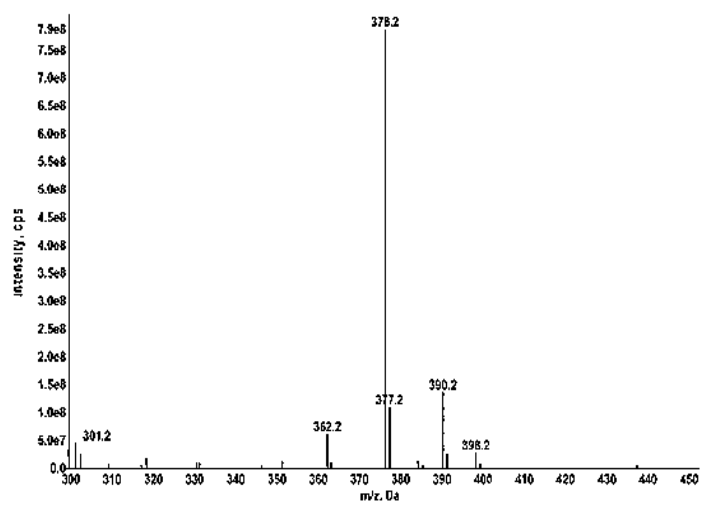

Figure 2: Positive ion ESI spectrum for tetra-methyl IBN prepared from working solution

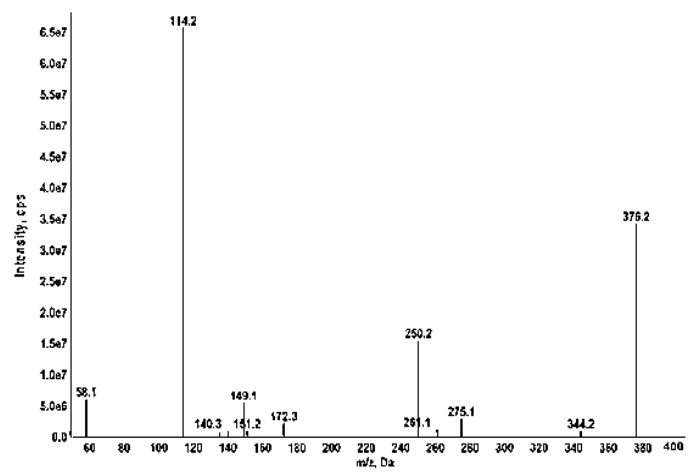

Figure 3: Product ion spectrum of IBN at collision energy of $28 \mathrm{eV}$

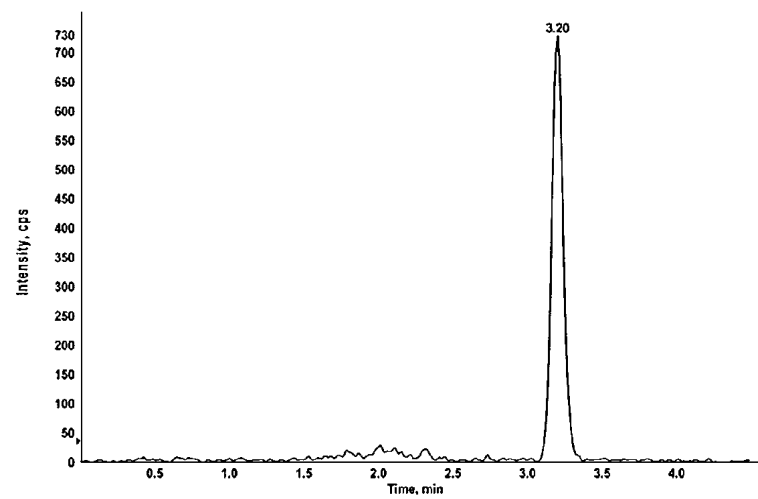

Figure 4: MRM shift of mass: charge ratio 376 to mass: charge ratio 114 for IBN derivative from plasma calibrator

\section{Selectivity}

Method selectivity was determined by testing interference from blank human plasma samples from 6 persons utilizing the proposed extraction and derivatization procedure and chromatographic protocols, and comparing with a standard solution of derivatized IBN. No interference was observed in the two transitions for IBN at their respective retention times.

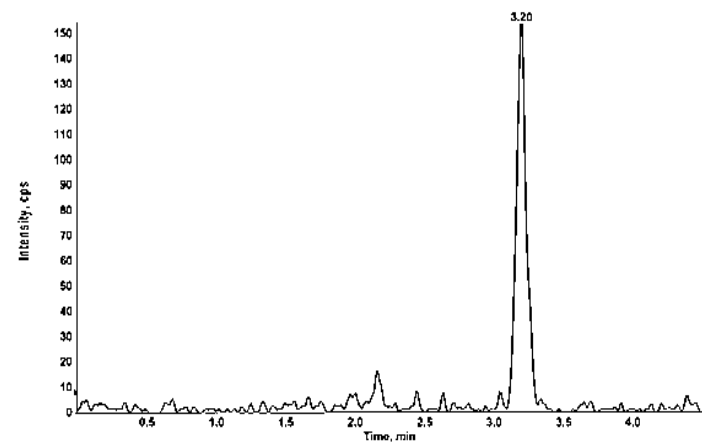

Figure 5: MRM shift of mass: charge ratio 376 to mass: charge ratio 250 for IBN derivative from plasma calibrator

\section{Matrix effect}

Six plasma samples from different donors were processed as indicated under sample preparation without the addition of analyte. The final extract of each sample was spiked with IBN standard at two distinct concentrations of 3.0 and $160 \mathrm{ng} / \mathrm{mL}$. Standard solutions of IBN (at the same concentrations) in mobile phase were prepared by the same approach. Each of the plasma sample extracts was then injected into the mass spectrometer, and peak areas for analyte were measured. Each of the standard solutions was injected three times and peak areas were averaged. Table 1 shows that there were no significant differences in peak areas amongst different plasma samples and standard solutions, indicating that if the analyte was coeluting with any endogenous materials, this did not significantly affect the ESI ionization. The average matrix effect for the IBN concentrations was $110.6 \%$.

\section{Linearity}

This was measured using six calibration curves containing eight non-zero concentrations. The analyte concentrations were calculated using weighted least squares regression analysis.

Table 2 shows summary of the calibration curves obtained during pre-study validation phase. Figure 6 shows six overlaid calibration curves 
obtained during pre-study validation phase. The excellent precision and accuracy obtained for such a large number of QC samples clearly show the ruggedness of the assay, despite the lack of an internal standard and the number of days that it took to analyze volunteer samples, involvement of two different analysts in sample extraction and derivatization, and the large number of solid phase columns used. The data also reflect the stability of the mass spectrometer.

\section{Accuracy and precision}

Accuracy was calculated in terms of mean, while precision was estimated from the coefficient of variation (\% CV). The mean value for accuracy and CV for precision did not surpass $15 \%$ of CV. Table 3 and Table 4 show the inter-day and intraday precision and accuracy for IBN during prestudy validation phase.

Table 1: Matrix effect analysis at three IBN concentrations

\begin{tabular}{|c|c|c|c|}
\hline $\begin{array}{l}\text { Plasma } \\
\text { sample no. }\end{array}$ & $\begin{array}{l}\text { IBN peak } \\
\text { area } \\
(3 \mathrm{ng} / \mathrm{ml})\end{array}$ & $\begin{array}{c}\text { IBN peak } \\
\text { area } \\
(160 \mathrm{ng} / \mathrm{ml})\end{array}$ & \\
\hline 1 & 3857 & 78395 & \\
\hline 2 & 3975 & 74698 & \\
\hline 3 & 3757 & 72930 & \\
\hline 4 & 3953 & 82989 & \\
\hline 5 & 4133 & 77051 & \\
\hline 6 & 4191 & 78744 & \\
\hline $\begin{array}{l}\text { Average peak } \\
\text { area }\end{array}$ & 3977 & 77468 & \\
\hline $\begin{array}{l}\text { Average } \\
\text { standard } \\
\text { solution peak } \\
\text { area }\end{array}$ & 3655 & 68902 & \\
\hline Matrix Effect & 108.8 & 112.4 & 110.6 \\
\hline CV $(\%)$ & 4.10 & 4.52 & \\
\hline
\end{tabular}

Table 2: Summary of the calibration curves obtained in the pre-study validation

\begin{tabular}{lccc}
\hline $\begin{array}{l}\text { Curve } \\
\text { no. }\end{array}$ & Slope & Intercept & $\begin{array}{c}\text { Correlation } \\
\text { coefficient }\left(\mathbf{r}^{2}\right)\end{array}$ \\
\hline 1 & 512 & 29.1 & 0.9926 \\
2 & 475 & 44.8 & 0.9857 \\
3 & 556 & 5.14 & 0.9938 \\
4 & 533 & 119 & 0.9974 \\
5 & 550 & 82.8 & 0.9817 \\
6 & 561 & 211 & 0.9942 \\
Mean & 531.17 & 81.97 & 0.9909 \\
SD & 32.82 & 74.97 & 0.0060 \\
CV (\%) & 6.18 & -- & 0.60 \\
\hline
\end{tabular}

\section{Lower limit of quantification (LLOQ)}

The limits of detection and quantification in plasma were obtained. As the assay progressed, it was found that IBN was detected in all calibrators at a concentration of $0.5 \mathrm{ng} / \mathrm{mL}$, and consistently acceptable precision values were got when back-calculated, with signal-to-noise ratio at LLOQ consistently $>3$. Therefore, 0.5 $\mathrm{ng} / \mathrm{mL}$ was considered the limit of quantification (LLOQ). Levels below LLOQ were considered "below quantification levels". The upper limit of quantification (ULOQ) was $200 \mathrm{ng} / \mathrm{ml}$.

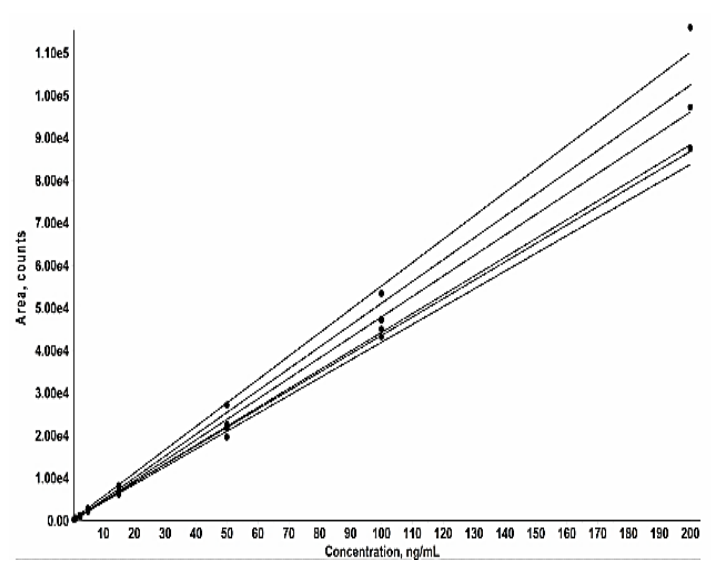

Figure 6: Calibration curves for IBN area $(n=6)$ at each concentration in the pre-study phase. This data was extracted directly from mass spectrometer analyst software by overlaying the 6 curves

Table 3: Inter-day precision and accuracy for IBN during pre-study validation phase

\begin{tabular}{lccccc}
\hline \multirow{2}{*}{ IBN } & $\begin{array}{c}\text { Nominal } \\
\text { conc. }\end{array}$ & \multicolumn{2}{c}{$\begin{array}{c}\text { Calculated } \\
\text { conc. }\end{array}$} & \multirow{2}{*}{$\begin{array}{c}\text { Accuracy } \\
\text { (\%) }\end{array}$} & $\begin{array}{l}\text { CV } \\
\text { (\%) }\end{array}$ \\
\cline { 3 - 4 } & & Mean $^{\mathbf{a}}$ & SD & & \\
\hline QC-L & 3.0 & 2.72 & 0.15 & 90.50 & 5.41 \\
QC-M & 80 & 86.37 & 6.25 & 107.96 & 7.23 \\
QC-H & 160 & 169.17 & 9.41 & 105.73 & 5.56 \\
\hline${ }^{a} \mathrm{n}=$ six replicates at each concentration $(\mathrm{ng} / \mathrm{mL})$ &
\end{tabular}

\section{Recovery}

Recovery refers to the effectiveness of IBN extraction using the designed analytical method. It was assessed from 3 plasma concentrations, with the usual extraction procedure. Three plasma samples at each concentration were processed.

Working solutions of IBN were diluted with mobile phase to produce the same concentrations as the plasma samples, and they were derivatized and analyzed. Recovery was calculated as shown earlier. The average recovery across the three concentrations was 84 $\%$, and CV was $6.8 \%$, as shown in Table 5 . Tarcomnicu et al [9] reported a recovery of 65.3 $\%$ and CV of $5.7 \%$, with d3-IBN as an internal standard. 
Table 4: Precision and accuracy (intra-day) for IBN during pre-study validation phase

\begin{tabular}{llllll}
\hline IBN & $\begin{array}{l}\text { Nominal plasma } \\
\text { concentration } \\
(\mathbf{n g} / \mathbf{m L})\end{array}$ & \multicolumn{2}{l}{ Calculated concentration } & Accuracy (\%) & \multicolumn{2}{l}{$\begin{array}{l}\text { Precision } \\
\text { (CV, \%) }\end{array}$} \\
\hline QC-L & 3.0 & Mean & & & \\
QC-M & 80 & 2.68 & 0.22 & 89.39 & 8.31 \\
QC-H & 160 & 85.12 & 5.35 & 106.40 & 6.29 \\
\hline
\end{tabular}

${ }^{\mathrm{a}} \mathrm{n}=\mathrm{six}$ replicates at each concentration

Table 5: Relative recovery results for IBN

\begin{tabular}{|c|c|c|c|c|}
\hline \multirow[b]{2}{*}{ IBN } & \multicolumn{2}{|c|}{ Area response (SD) } & \multirow[b]{2}{*}{$\begin{array}{c}\text { Recovery } \\
(\%)\end{array}$} & \multirow[b]{2}{*}{$\begin{array}{l}\text { CV } \\
(\%)\end{array}$} \\
\hline & $\begin{array}{c}\text { Derivatized } \\
\text { extracted } \\
\text { plasma }^{a}\end{array}$ & $\begin{array}{l}\text { Derivatized } \\
\text { standard }\end{array}$ & & \\
\hline $\begin{array}{l}\text { QC- } \\
L\end{array}$ & 1970 & 2347 & 83.93 & 2.95 \\
\hline $\begin{array}{l}Q C- \\
M\end{array}$ & 112444 & 132186 & 85.064 & 1.85 \\
\hline $\begin{array}{l}\text { QC- } \\
\mathrm{H}\end{array}$ & 160929 & 194610 & 82.69 & 0.90 \\
\hline
\end{tabular}

\section{Stability}

Stability was assessed in the plasma samples under different timing and temperature conditions. To test stability, a series of standard samples were analyzed. The respective low, medium and high-quality controls were used. Autosampler stability (Table 6) was assessed using the processed quality control plasma samples at $4{ }^{\circ} \mathrm{C}$, and anticipated batch run time up to $12 \mathrm{~h}$. The results indicate that the analyte was stable in the autosampler for up to $12 \mathrm{~h}$ without significant loss. The average stability of the concentrations tested was $95.6 \%$.

Table 6: Auto-sampler stability data

\begin{tabular}{lccc}
\hline IBN & \multicolumn{3}{c}{ Calculated concentration $(\mathbf{n g} / \mathbf{m l})^{\mathbf{a}}$} \\
\cline { 2 - 4 }$(\mathbf{n g} / \mathbf{m L})$ & Fresh & $\mathbf{1 2} \boldsymbol{h}$ & Stability \% \\
\hline $\begin{array}{l}\text { QC-L } \\
\text { (3.0) }\end{array}$ & 3.15 & 3.26 & 103.49 \\
$\begin{array}{l}\text { QC-M } \\
\text { (80) }\end{array}$ & 85.72 & 78.98 & 92.14 \\
$\begin{array}{l}\text { QC-H } \\
(160)\end{array}$ & 187.00 & 170.40 & 91.12 \\
\hline an = 5 at each concentration for each experiment
\end{tabular}

As shown in Table 7, the analyte in human plasma was stable at RT for up to $24 \mathrm{~h}$.
Long term stability (Table 8 ) was tested at $-24{ }^{\circ} \mathrm{C}$ for 30 days. The results indicated that the drug in plasma samples was sufficiently stable at all three concentrations tested when kept at $-24{ }^{\circ} \mathrm{C}$ for a relatively long time and then thawed to room temperature. The average long-term stability at three concentrations was $98.7 \%$, with CV of $12.8 \%$.

To evaluate short term and long term IBN stabilities of working solutions, one working solution (IBN-1) was freshly prepared $(50 \mu \mathrm{g} / \mathrm{mL})$ and analyzed immediately. Then, portions were allowed to stand at room temperature for $6 \mathrm{~h}$ and $24 \mathrm{~h}$, and then analyzed. A third portion was stored at $-24{ }^{\circ} \mathrm{C}$ for 30 days prior to analysis. On day 30, two working solutions were freshly prepared and analyzed against the aged solutions. All solutions were analyzed five times, and the results are presented in Table 9. The results were based on the determination of IBN areas. The average working solution stability was $101.9 \%$.

The results of freeze-thaw stability are shown in Table 10 which indicates the freeze and thaw stability limitations. The 3 freeze-thaw cycles resulted in mean stability difference $<15 \%$.

\section{DISCUSSION}

Ibandronate (IBN) was obtained from plasma with weak anion exchange SPE columns with 'on-cartridge' derivatization using tri-methylsilyldiazomethane (TMS-DZ) reagent to convert IBN to tetra-methyl derivative. The eluate of SPE was evaporated to dryness, reconstituted in mobile phase, and an aliquot was analyzed using electrospray ionization liquid chromatography tandem mass spectrometry (LC-MS/MS) in positive ion mode. Plasma calibrators and quality

Table 7: Short-term stability data

\begin{tabular}{lccccccc}
\hline \multirow{2}{*}{ IBN (ng/mL) } & Fresh & $\mathbf{6} \boldsymbol{h}(\boldsymbol{R T})$ & Stability (\%) & $\mathbf{2 4} \boldsymbol{h} \mathbf{( \mathbf { 4 } ^ { \mathbf { O } } \mathbf { C } )}$ & $\begin{array}{c}\text { Stability } \\
\mathbf{( \% )}\end{array}$ & $\mathbf{2 4} \mathbf{h}(\mathbf{R T})$ & Stability (\%) \\
\cline { 2 - 8 } & & 2.58 & 91.81 & 2.70 & 96.38 & 3.23 & 115.15 \\
QC-L (3.0) & 2.81 & 78.27 & 96.39 & 73.67 & 90.72 & 84.40 & 103.94 \\
QC-M (80) & 81.20 & 153.67 & 91.83 & 157.67 & 94.22 & 177.33 & 105.98 \\
QC-H (160) & 167.33 & 153 &
\end{tabular}


Table 8: Long-term stability results

Table 9: Stability of IBN working solutions

\begin{tabular}{|c|c|c|c|c|c|c|}
\hline \multirow{3}{*}{ IBN (ng/mL) } & \multicolumn{3}{|c|}{ Calculated concentration $(\mathrm{ng} / \mathrm{mL})^{\mathrm{a}}$} & \multirow{2}{*}{ IBN $(50 \mu g / \mu L)$} & \multirow{2}{*}{$\begin{array}{c}\text { IBN peak area }{ }^{a} \\
\text { Mean (SD) }\end{array}$} & \multirow[b]{2}{*}{ Stability } \\
\hline & \multirow{2}{*}{ Fresh } & \multirow{2}{*}{$\begin{array}{l}30 \text { days } \\
\left(-24^{\circ} \mathrm{C}\right)^{a}\end{array}$} & \multirow{2}{*}{ Stability (\%) } & & & \\
\hline & & & & Day zero & 410263 (6783) & -- \\
\hline QC-L (3.0) & 2.81 & 3.18 & 113.17 & $6 \mathrm{~h}(\mathrm{RT})$ & $385578(3516)$ & 93.98 \\
\hline QC-M (80) & 82.37 & 73.73 & 89.51 & $24 \mathrm{~h}(\mathrm{RT})$ & $410858(2744)$ & 100.14 \\
\hline \multirow{2}{*}{ QC-H (160) } & \multirow{2}{*}{$\begin{array}{c}167.3 \\
3\end{array}$} & \multirow{2}{*}{156.33} & \multirow{2}{*}{93.43} & 30 Days zero & $297020(11570)$ & -- \\
\hline & & & & 30 Days $\left(-24^{\circ} \mathrm{C}\right)$ & $331052(9377)$ & 111.46 \\
\hline
\end{tabular}

Table 10: Freeze and thaw stability for IBN

\begin{tabular}{|c|c|c|c|c|c|}
\hline \multirow[b]{2}{*}{ IBN } & \multicolumn{5}{|c|}{ IBN concentration $^{\mathrm{a}}$} \\
\hline & $\begin{array}{c}\text { Nominal concentration } \\
\text { in plasma }(\mathrm{ng} / \mathrm{mL})\end{array}$ & Fresh & $\begin{array}{l}\text { After } 3 \\
\text { cycles }^{a}\end{array}$ & Stability (\%) & $C V(\%)$ \\
\hline QCM & 80 & 82.0 & 79.93 & 97.48 & 5.0 \\
\hline $\mathrm{QCH}$ & 160 & 155.33 & 147.00 & 94.64 & 16 \\
\hline
\end{tabular}

${ }^{a} n=3$. Tests performed indicated that the mean freeze-thaw stability at two concentrations was $96.1 \%$

control (QC) plasma samples were prepared in control human plasma in the expected concentration range, and were treated in the same way. Stringent sample handling and processing enhanced the full validation of this assay and maintained accuracy and precision throughout the work. Bioanalytical method validation was performed with respect to selectivity, matrix effect, linearity, accuracy, precision and stability. Sample preparation technique plays an important role in successful application of the method. The solid phase extraction technique provides substantial advantages over conventional liquid-liquid extraction. These advantages include high selectivity, high recoveries and sensitivity.

\section{CONCLUSION}

This work offers a method for extracting IBN from human plasma using SPE, thereby overcoming the drawbacks associated with previously published methods for determination of IBN. Conditions used for LC-MS/MS were optimized to get maximum sensitivity and precision. Validation parameters such as autosampler, freeze and thaw, and short- and long-term stability showed that there was no appreciable degradation at the temperatures and time periods specified and described in the method. This validated LC-MS/MS method is suitable for analysis of IBN in pharmacokinetic studies. It is a sensitive and specific assay for plasma IBN in bioequivalence studies.

\section{DECLARATIONS}

\section{Acknowledgement}

This project was supported by the Deanship of Scientific Research at Prince Sattam bin Abdulaziz University under Research Group no. 2016/03/6600.

\section{Conflict of interest}

No conflict of interest is associated with this work.

\section{Contribution of authors}

We declare that this work was done by the authors named in this article and all liabilities pertaining to claims relating to the content of this article will be borne by the authors.

\section{Open Access}

This is an Open Access article that uses a funding model which does not charge readers or their institutions for access and distributed under the terms of the Creative Commons Attribution License (http://creativecommons.org/licenses/by/ 4.0) and the Budapest Open Access Initiative (http://www.budapestopenaccessinitiative.org/rea d), which permit unrestricted use, distribution, and reproduction in any medium, provided the original work is properly credited. 


\section{REFERENCES}

1. Constantino KZ, Paraskevas TZ. Determination of bisphosphonate active pharmaceutical ingredients in pharmaceuticals and biological material: $A$ review of analytical methods. J Pharm Biomed Anal 2008; 48: 483-496.

2. Cranney A, Wells GA, Yetisir E, Adami S, Cooper C, Delmas PD, Miller PD, Papapoulos S, Reginster JY, Sambrook $P N$, Silverman $S$, Siris E, Adachi JD. Ibandronate for the prevention of nonvertebral fractures: a pooled analysis of individual patient data. Osteoporos Int 2009; 20: 291-297.

3. Ptacek $P$, Klima J, Macek J. Determination of alendronate in human urine as 9-fluorenylmethyl derivative by high-performance liquid chromatography. $J$ Chromatogr B 2002; 767: 111-116.

4. Norihisa S, Hiroyuki K, Masami M. Gas chromatographic analysis of 3-amino-1-hydroxypropylidene-1,1bisphosphonate and related bisphosphonate as their $N$ isobutoxycarbonyl methyl ester derivatives. J Chromatogr A 1996; 724: 279-284.

5. Bertinatto Rodríguez JA, Desimone MF, Iglesias SL, Giorgieri SA, Diaz LE. Validation of a capillary electrophoresis method for the analysis of ibandronate related impurities. J Pharm Biomed Anal 2007; 44: 305308.
6. Endele $R$, Loew $H$, Bauss $F$. Analytical methods for the quantification of ibandronate in body fluids and bone. $J$ Pharm Biomed Anal 2005; 39: 246-256.

7. Moktar M, Sherin FH, Mohamed AA, Fotouh RM. Indirect Spectrophotometric Determination of Ibandronate in Pharmaceutical Formulations via Ligand Exchange. Anal Chem Lett 2019; 9: 223-233.

8. Tarcomnicu I, Silvestro I, Savu SR, Gherase A, Dulea C. Development and application of a high-performance liquid chromatography-mass spectrometry method to determine alendronate in human urine. $J$ Chromatogr $A$ 2007; 1160: 21-33.

9. Tarcomnicu I, Gheorghe MC, Silvestro L, Savu SR, Boaru I, Tudoroniu A. High-throughput HPLC-MS/MS method to determine ibandronate in human plasma for pharmacokinetic applications. J Chromatogr B 2009; 877: 3159-3168.

10. Jonsson JA, Mathiasson L. Liquid membrane extraction in analytical sample preparation. TrAC Trend Anal Chem 1999; 18: 318-325.

11. Wasylka JP, Szczepańska N, Guardia M, Namieśnik J. Miniaturized solid-phase extraction techniques. TrAC Trend Anal Chem 2015; 73: 19-38.

12. Lee SZ, Veniamin $N L$, Jean WL, Yousef JB, Chris $K$, Richard O, Chad B. A general approach for the quantitative analysis of bisphosphonates in human serum and urine by high-performance liquid chromatography/tandem mass spectrometry. Mass Spectrom 2006; 20: 3421-3426. 